\title{
Challenges for Creating and Staging Interactive Costumes for the Theatre Stage
}

\author{
Michaela Honauer, Eva Hornecker \\ Bauhaus-Universität Weimar, Fak. Media. Bauhausstr. 11, 99423 Weimar, Germany \\ michaela.honauer@uni-weimar.de, eva.hornecker@uni-weimar.de
}

\begin{abstract}
In this paper, we discuss the requirements and critical challenges for creating and staging interactive costumes in the theatre. Different to other types of performance, theatre costumes are secondary to acting. Our investigations are based on two practice-based case studies: a self-directed design research within a student project, and a collaboration with a local theatre house, where interactive costume elements were developed in a real-life setting. These reveal requirements and challenges for the design process as well as the effective staging of interactive costumes, the biggest challenge being how to integrate these into existing structures of traditional theatre houses, and requirements for the costumes themselves. Because interactive costumes integrate technological features and traditional analogue crafts, they require interdisciplinary collaboration and transcend established boundaries between departments in theatre houses, challenging established work processes and structures.
\end{abstract}

\section{Author Keywords}

Theater Performance; Design Research; Wearables; Interdisciplinary Collaboration; Crafts.

\section{INTRODUCTION}

The evolving potential of e-textiles and wearable computing is a growing topic in HCI and related areas. There are dozens of examples but many are technical demos $[6,19]$, proofs of principle [3], or fashion prototypes [15] and art pieces $[4,28]$. Beyond these, the potential of computational clothing for specific applications still needs to be demonstrated; in particular we need to ensure that it can integrate into existing practices and infrastructures. Such practices are highly situated [26], requiring us to engage with specific real world application areas and scenarios.

Currently, there are only such few case studies, most of which focus on healthcare and fitness, where wearable gadgets (e.g. the fitbit) are more dominant than interactive

\footnotetext{
Permission to make digital or hard copies of all or part of this work for personal or classroom use is granted without fee provided that copies are not made or distributed for profit or commercial advantage and that copies bear this notice and the full citation on the first page. Copyrights for components of this work owned by others than the author(s) must be honored. Abstracting with credit is permitted. To copy otherwise, or republish, to post on servers or to redistribute to lists, requires prior specific permission and/or a fee. Request permissions from Permissions@acm.org.

$C \& C^{\prime} 15$, June 22 - 25, 2015, Glasgow, United Kingdom

Copyright is held by the owner/author(s). Publication rights licensed to ACM.

ACM 978-1-4503-3598-0/15/06 ..\$15.00

DOI: http://dx.doi.org/10.1145/2757226.2757242
}

clothing itself [12], and a few research projects are related to gaming [6]. In our own work we are interested in the potential aesthetic and creative uses and role of interactive clothing as a new medium. This has led us to explore its use within the context of theatre. Theatre is one of the oldest entertainment forms, and from early-on costumes were an element of performance. It is an interesting application area because theatre organizations create their own costumes, relying on existing practices and crafts. This allows us to investigate what challenges interactive costumes might pose for these practices and for theatre infrastructures.

In this paper we discuss critical challenges and requirements for creating and staging interactive costumes for theatre stages. In this context, we understand interactive costumes as theatre costumes that are enhanced with computational components that can be controlled by their wearer. Our interest here is less in the technology as such, than in the (creative) design process for interactive costumes, and in how these could fit into the practices of professional theatre to fulfill their potential as a new medium in this domain. As this is still a novel topic for theatre houses and for research, there are a number of larger scale research questions that our work is beginning to address: How do we best go about designing/developing interactive costumes? How do their users (wearers $=$ actors) adopt them and what needs do they have? How can such costumes and their development become an integral part of the routines and organizational structures of professional theatre houses?

Our findings are based on the experiences made in two projects, each employing a different approach. The first is an interdisciplinary student project at the Bauhaus-Universität Weimar using a research-in-and-through-design approach. It aimed at arriving at an ensemble of costumes that can be imagined by their end users (actors) to be used on stage. The second project, a collaboration with a local theatre house, the Theaterhaus Jena, used an ethnographically oriented action-research approach, where we assisted in developing electronic components for costumes for two productions. This allows us to compare the student project's self-directed development process, which could explore how to best go about developing interactive costumes, with the practices and institutional constraints of a theatre house. We describe our experiences and findings regarding the aforementioned research questions regarding the creation process for interactive costumes and their adaption by actors. In particular, various frictions in the theatre collabora- 
tion highlight the critical role of the application context's socio-technical-organizational infrastructure.

\section{BACKGROUND}

\section{Interactive Theatre and Performance Arts}

While visions of interactive theatre have emerged in the literature $[8,21,24,27]$, these mainly refer to stage design and predominantly utilize visual projections. A noticeable number engage the audience to influence the outcome of a piece $[8,21]$. But in our literature overview we did not find any projects that integrate interactive costumes.

This is different in performance arts, where computational systems often relate to the performer's body [1, 4, 16, 28]. The majority attaches technologies to the performer and generates audio feedback from movement [4]. Such examples can be categorized as wearable computing. Wearable sensors have been used in digital music performances for 30 years [23]. Many projects make use of costume-like elements, e.g. "helmets with mirrored eyepieces that allow the wearer to shift her focus onto herself" [23] that can be categorized as technical wearables although no computational components are included. Nowadays, artists use the human body as a surface for projections [1] often relying on camera-based tracking. A few projects integrate light output into the performers costumes, usually with LEDs and lightstrips [16]. The light-arrays suit [28] goes beyond this with integrated laser beams that dynamically project into the environment. A number of specialized performance groups utilize electronics as a key artistic feature and core of performance, typically in dance, acrobatic, or music shows.

Other research investigates how spectators perceive interactive elements of a performance. Benford and Giannachi reflect on how the boundaries of the stage disappear as well as those between spectators, actors and other participants/players in participatory performances [2]. Spectators may experience interactions as secretive, expressive, suspenseful or magical, depending on the visibility of interface manipulations and their effects, which each may be hidden, partially or fully revealed, and amplified [22].

\section{New Challenges for Traditional Theatres}

One of our primary interests lies in how traditional theatre houses can incorporate interactive costumes into their production processes. These differ from performance art and specialized troupes in their professional practice. The organizational structures in theatre houses have developed historically and tend to clearly separate different creative responsibilities (e.g. costume/stage design) from technical areas (lighting technician, sound engineering). Many departments produce a piece in a coordinated process but their work is only integrated in the final rehearsals [14]. All responsibilities in the production are separated by departmental competencies and professional expertise. The process seems optimized to enable parallel work on different components with minimal interdependency and maximal autonomy for each department [17]. This constitutes the in- frastructure, embedded in social structures and taken-for granted organizational arrangements $[14,17]$ that any attempt to introduce interactive costumes to traditional theatres will have to integrate into [11]. How much of a challenge this poses was revealed by our theatre collaboration.

\section{TWO CASE STUDIES OF INTERACTIVE COSTUMES}

In this section we describe our experiences and insights from creating and staging interactive costumes. These were gained from two parallel studies in different contexts. The first is a four month student project supervised by the authors, where interdisciplinary teams developed interactive costumes. The project goal was to explore the creative process and to evaluate the prototype costumes in a workshop with 'real' actors. This self-directed development can be characterized as a research-in-and-through-design process [7], as our research concerned the design process itself while the results (the costumes) were the base for further knowledge generation [29]. The other study combined ethnographic-oriented participant observation with an action research approach $[9,13]$. One member of the research team worked one month as intern at the Theaterhaus Jena, a theatre house interested in integrating interactive technologies into their program and continued to collaborate as external designer over the next five months. Here, interactive costume elements were developed in a real-life theatre setting, in collaboration with its staff, and our experiences highlight frictions with existing organizational structures and professional practices. In the following, we present the student project, followed by the theatre collaboration and discuss the ideation, development, and deployment/staging phases for each study, as well as the lessons learned.

\section{A Self-Directed Design Process in a Student Project}

In this research project, students from Applied Computer Science, Media Arts/Design, and Product Design developed costumes for the story Twenty Thousand Leagues under the Sea by Jules Verne (figure 1). At the onset, they were organized into three teams of one product/media design and two technology students each in order to work from the start in small interdisciplinary teams so technology and design ideas could be developed hand in hand. Design should push technical possibilities and technology ideas influence the designs. In hindsight, it also turned out that this helped teams to quickly figure out whether an idea was feasible. We first give an overview of the costumes created, before detailing the design process and the insights gained.

- Captain Nemo is the captain of the Nautilus submarine. His 'living' robe is made of sea creatures such as anemones (figure 1B). It can glow in the dark underwater world, and vibrates if enemies approach. A simple light sensor activates the lights. A distance sensor controls vibrating motors under the robe. All features can be dis-/enabled by the actor by pushing a button hidden in the costume.

- The Diving Suit is worn by the Nautilus Crew (figure 1D). Its jacket has a fin- or rib-like pattern that glows 


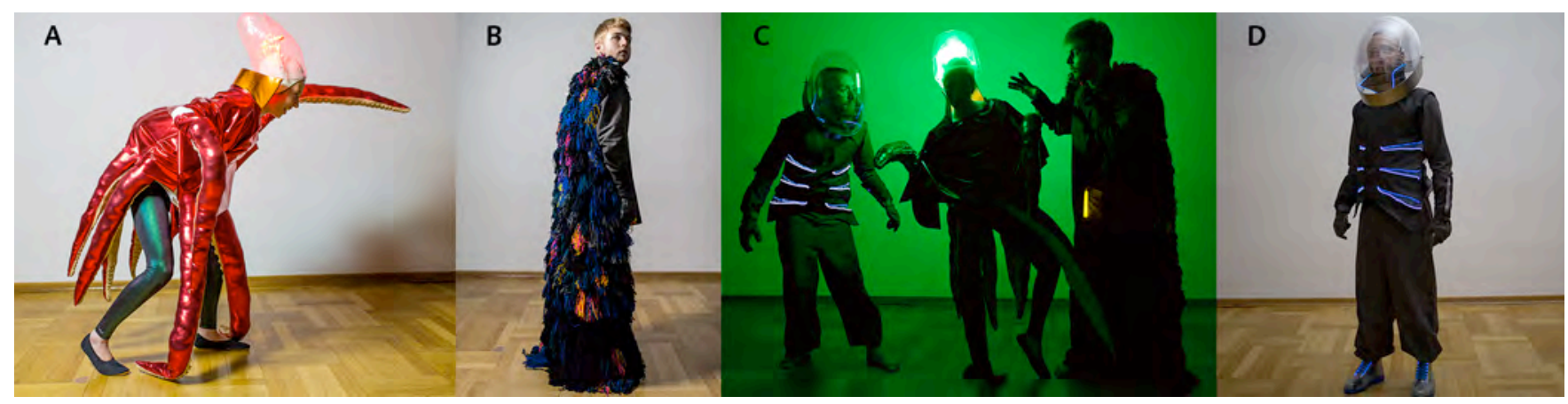

Figure 1. Octopus (A), Captain Nemo (B), and all costumes together (C), Diving Suit (D)

blue in water and white on land. These modes indicate whether the helmet is open or closed and are activated via a button on the jacket at chest height. The diver wears an oxygen tank with two chambers, one delivering air while the other chamber regenerates. The tank is controlled via a display on the suit's glove. LEDs show the active fill level and a button allows switching chambers.

- The Octopus Sea Creature is the antagonist living alone and roaming through the deep sea. It can move two tentacles at its front (motorized skeletons are integrated, operational mode see figure 3 ). As an animal cannot talk, the octopus' brain glows according to its moods - green when relaxed, yellow when attentive and red if aggressive. Two dials control these functions, both hidden in the costume sleeves that the actress puts her arms into.

\section{Ideation and Background Research (ca. 4 weeks)}

As most of the students had no prior experience with theatre, it was important to first gain a better understanding of the domain. This included a sense of what it is like to be acting, and understanding the role of costumes in theatre. This phase therefore included field observation and handson activities as a form of background research. In parallel, the students decided on a general theme for their work, picking the deep sea and then quickly settling on the Captain Nemo story and the three characters. Some basic ideas for the costumes emerged in this phase, such as using EL wire and the living robe. Working in interdisciplinary teams from the very start, technology and design ideas came from both sides, as technology students explained aesthetical concepts and designers described technological features.

To learn more about the role of costumes, we visited two different plays at a local theatre, focusing on three costumes. From observations, it became clear that the costumes often conveyed cultural, social or historic meaning, such as social status and emotional state. For example, a dirty corset and overlong multilayered but torn skirt worn by a poor woman indicated that she had once been affluent. The dirty and torn garments of another character meant he had problems. When his clothes were clean, his condition was more stable. Moreover, the mentioned corset and overlong skirt affected the actress' postures and movements, embodying the restrictions of societal conventions: she could not run and had to lift up the skirt to turn around. In another play the actors changed clothes very often on or behind the stage. We concluded that costumes should be very robust as they are typically worn and cleaned repeatedly, or need to be changed quickly. Furthermore, hairstyle, hats, shoes, and jewelry also influence a character's appearance and hence are part of costume. Overall, costumes emphasize a character's status or mood, while influencing actors' movement and behavior [14], as well as supporting (non)verbal communication to other actors or the audience.

We also attended a two-day design-acting workshop run by a drama educator/ theatre pedagogue practitioner. This introduced students to a range of acting techniques, such as improvisation and role-play. Students improvised based on their initial character ideas. We further experimented with costumes, using a few objects (rope, scarf, coconut, wooden sticks, aluminum foil). Overall, this workshop gave students deeper insights into the practice of acting and some firsthand experience. We realized that playing a role is an actress' main task on stage demanding full concentration. Thus, the costume is subordinate to the activity of acting and it should never require full or focused attention.

\section{Development Phase (10 weeks)}

The development phase included a synthesis of design and technical development. It began with a 2-3h bodystorming [25] and tinkering session in which students constructed simple costume prototypes from cheap everyday materials, put them on, and experimented what kind of garments might fit with their character. From this activity, students identified solutions for integrating technical elements into the costumes. For instance, the octopus should be able to move the motorized front tentacles. In this session we decided to hide the technical construction under a cape (figure 2A/B). Similarly, bodystorming the diver suit (figure 2C) had the students imagine wearing a helmet and inspired the idea of making it retractable (figure 2D). Experiencing early costume prototypes with our own body and movements was helpful to understand and improve costume concepts.

Following this, student teams began to work on the detailed prototypes. All teams investigated materials and fabrics that evoke the deep-sea theme. The students experimented with different physical phenomena (e.g. the behavior of flexible 


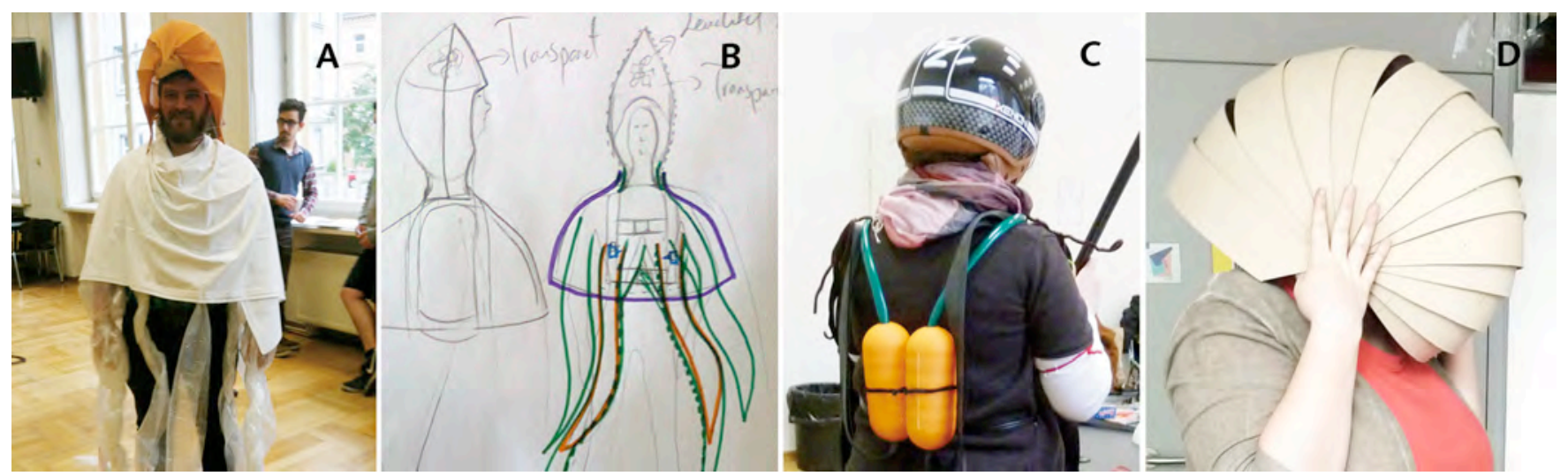

Figure 2. Octopus - lo-fi prototype (A) and early sketch (B). Diving Suit - bodystorming (C) and cardboard mockup of helmet (D).

shafts for the octopus arms) and hacked electronic components (e.g. connecting electroluminescent wire to an Arduino) to realize their concepts. Technical and design ideas developed step by step. For instance, the captain's costume has lots of fringes on the shoulders that are to glow and move. The test of an early prototype (figure 4) revealed this was hardly visible from a distance. The audiences' point of view needs to be considered when designing interactive costumes. While the audience does not need to understand how an effect works, it needs to see, hear or feel it. The students thus created a longer robe (figure 1B) and inserted a second textile layer with ten vibration motors underneath.

During this process, we repeatedly discussed how much feedback the wearer would need for their actions. Some costumes create light effects outside of the wearer's visual field - the actor inside the octopus costume cannot see her glowing head and the diver has a two-chambered oxygen tank on his back. A feedback display was added to the diver's glove, with LEDs showing the fill level of the active chamber and a button to switch chambers. In contrast, the octopus team decided for purely haptic interaction via a dial with a tangible start and end value, and visual feedback provided from the environmental reflection of the glowing head in the dark (see figure 1C where the environment is green from the head's glow).

Towards the end of this process, we visited a professional costume designer at a theatre. We explained some of our concepts and how we had realized these to the costume designer. She provided elaborated feedback and sewing and

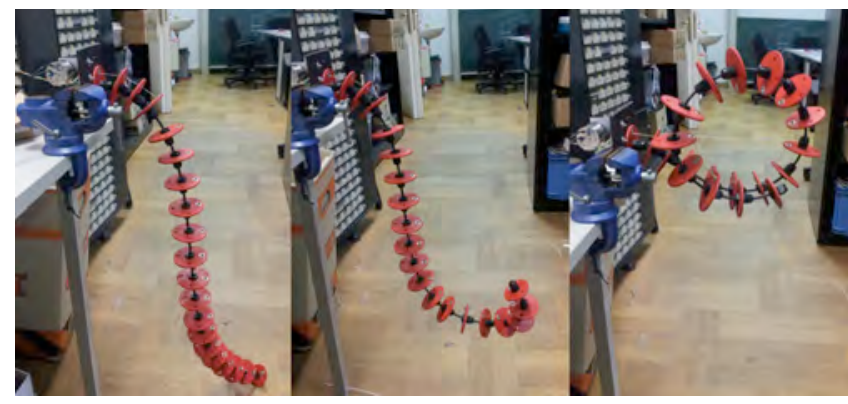

Figure 3. Octopus' skeleton: Sequence of smooth movements. tinkering tips. In retrospect, meeting her complemented the final production phase with aesthetical aspects. Furthermore, she provided insights into her daily work, and explained her work routines with the director, tailor or dresser (who helps the actors to dress). It turned out that her creative process hardly ever overlaps with technical staff. She thus was impressed by our cooperative work. We had found that establishing working routines between design and technology students early-on ensured a fruitful collaboration. Most confirmed that they gained insights into the other discipline. Design students developed costume ideas that were unfinished until the engineers in the team merged the technical features into the textiles.

\section{Deployment/ Staging}

The last phase involved having the users' (i.e. actors) encounter and wear the costume prototypes in a one-day workshop. This revealed benefits and critical factors for introducing interactive costumes to the stage. The drama educator supported us again in the preparation and during the workshop itself, for which we invited actors that would improvise, rehearse and then perform a short play while wearing our costumes. With the drama educator, we developed a short plot for the play, designed the workshop procedure and prepared interview questions. We chose a mix of observation, interviews and group discussion to analyze how the actors appropriate the costumes.

Three semi-professional actors took part in the workshop. The first hour was reserved for getting to know each other, and letting the actors explore, put on, and experience the

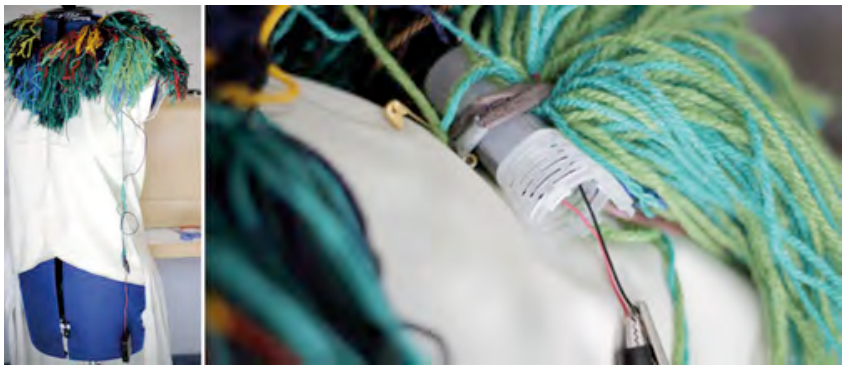

Figure 4. Early working prototype of Nemo's costume 
costumes. We first withheld from explanations. Then, our teams explained all interactive features step by step. Next, the drama educator introduced the story plot, and guided the improvisation, rehearsals and a final performance for the next few hours, while we helped organizing, made notes, and held the interviews with the actors. We video-recorded everything from first contact over rehearsals to final performance and interviews.

From the initial first exposure on, the actors reacted very open-minded and positive. They were curious to discover all features and immediately understood most explanations. They seemed impressed by simple features, such as LED light. For instance, once the actress wearing the octopus costume was familiar with changing the color of her head, she showed it to a colleague who was very surprised. This may be because the manipulation mechanism is invisible, hidden in a costume sleeve (Reeve et al.'s magical spectator experience [22]). Moreover, all actors confirmed it was the first time they ever had contact with interactive costumes.

In this workshop, our user group tested our prototypes, but subordinated to their task of improvising and performing a new play. They started moving as if floating under water, in slow motion, to get into 'living in the sea'. Our observations indicate that the shape and appearance of the costumes supported the actors in their task. For instance, when in the 'deep sea' Captain Nemo stooped, ducking his head into his wool-tentacled shoulder as if listening to his 'living robe' (figure 5). The weight and size of the robe seemed to facilitate this posture. Also, over time the actors became more confident using the interactive features. This means rehearsing with the technology is just as necessary as rehearsing the text and choreography of a play.

Furthermore, the computational components only had a minor role while the actors learned to play a character. They never stopped the rehearsals because of technical problems. Any technical issues were solved in the breaks or between scenes. A reason for this could be the basic rule that an actor should always continue acting despite of whatever happens. This relates to our earlier observation at the local theatre house. In other words, costumes support an actress in playing a role, but she should express her role primarily through her performing skills and not rely on a costume.

The final individual semi-structured interviews with all actors asked their opinions about the costumes, ranging from aesthetical aspects over technical understanding to usability. In general they liked the costumes and thought their features enhanced the performance. A central theme emphasized by all actors concerns wearability and freedom of movement. The diver felt the rigidness of the backpackhelmet construction and captain Nemo felt the weight of his robe (figure 5). Yet both seemed to be comfortable and explained this helped them immerse into their role, as this would be what the character experiences. This verifies our observation from the rehearsals. There thus is a tradeoff for wearability, as it can be the cumbersomeness of a costume and the restrictions it poses for movement that support the actor in immersing themselves in a role.

The answers to how much feedback is needed differed for all costumes. The actress wearing the octopus said she got a feeling for the colors in her head after training with the dial, and, as assumed, could see the light reflections in the environment. She stated an additional feedback would probably distract her from acting. On the other hand, the actor with the diving suit thought the display in his glove suited playing a diver who would probably want to check and control his oxygen tanks. Again, we conclude that interactive costumes should support actors in expressing their character instead of distracting them, and hence the amount of feedback provided depends on individual role-related decisions.

A last finding concerns inhibition of technology and worries about lack of control. All actors offered diverse thoughts on where control should be located. The diver actor thought that sometimes it might take too much concentration to act and simultaneously control the costume features. Rehearsing would improve this to an extent, but it likely also depends on the complexity of actions on stage. The actor wearing Nemo's costume told that he was irritated if the light in his robe worked and didn't the next moment because of technical issues. While this was not noticeable from a spectator's viewpoint, he did not feel comfortable. Thus, interactive costumes need to work reliably before giving them to actors. Also, it could be helpful to tell an actress beforehand what kind of technical issues could arise and pre-plan how to deal with these. Finally, the octopus actress raised concerns over the motorized tentacles. She was afraid to loose control or activate the mechanism accidentally and said that she needs to test this feature often enough to get familiar with it. All of this points to the need for substantial rehearsing with interactive costumes.

Moreover, all actors made suggestions on how to improve the costume concepts or designs, either during rehearsals or interviews. For instance, the octopus actress pointed out that having the motorized tentacles on her back would give her more liberty than at the front where she needs space for her own gestures. This suggests that one should involve actors at an early stage to ask for their ideas and feedback

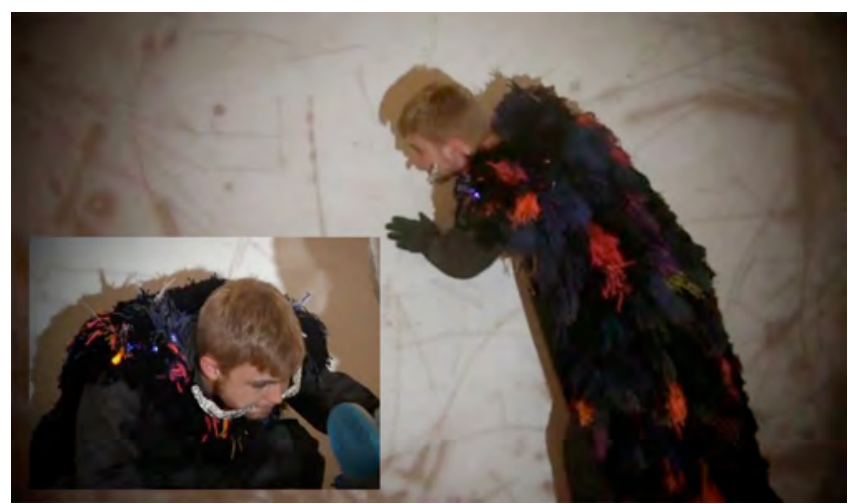

Figure 5. Nemo stoops, caused by the robe's shape and weight. 
when designing interactive costumes, thus following a more user-centered or participatory approach [13].

\section{Lessons Learned}

In general, costumes support actors in playing a role; they underline a character's appearance and status, influence movement and posture, but are subordinate to acting. Seen as a working garment, they must be very robust to withstand excessive use over at least a season. From a spectator's perspective, effects should be perceivable independent of their location in the audience.

Most actors are not used to deal with computational clothes. That's why the user (actor) needs background knowledge to handle this easily and requires appropriate feedback on their actions. This means we need to carefully introduce them to the new possibilities of interactive costumes. These should provide easy and intuitive input, appropriate feedback, and ensure enough freedom for acting and moving, while supporting immersion into the role. Above all, an actress should gain basic knowledge about a costume's technical operation as well as potential breakdowns, and should learn how to deal with these. Actors should rehearse early and often enough in the interactive costumes to get familiar with its features.

Moreover, our interdisciplinary collaboration ensured successful development. It is advantageous for designers and engineers to develop interactive costumes together from the start for ideas to be brought in and get reflected by both sides. Activity-based work, collaborative development and testing support teams to come up with individual design solutions for interactive costumes and to deal with functional issues. Finally, involving actors during the creation process would enable designers and engineers to get early user feedback and include these insights into their designs.

\section{Collaboration with a Theatre House}

In parallel to the student research project, one of the authors contributed to two productions at a local theatre house that was interested in exploring interactive elements. The Theaterhaus Jena is small ( $<50$ staff) but has traditionally structured departments, as most theatres do [14], with clearly defined responsibilities. This collaboration enabled us to experience professional theatre structures and outline further requirements for interactive costumes. In the following, we outline our role in the two productions, before detailing the design process and the insights gained.

(Panda Show) One of the authors spent a month as intern at the theatre to get an overview of the workflows behind stage and the different professional roles and viewpoints. Her task was to support the technical staff and produce video content for plays. She also became involved in creating an interactive costume for The Panda Bear Show where a panda mask was to have 'red-glowing eyes' (figure 7). The production of this play took six weeks whereof she was involved the last four; the premiere was in March 2014.
(King Ubu) The same author continued to participate as external designer in the production of King Ubu where the main character was to wear a fat-man suit that can 'smoke from its armpits and rear' (figure 6). This play was produced in around three months but we started discussing ideas a few weeks earlier; the premiere was in July 2014.

\section{Ideation Phase}

We started discussing ideas for both productions processes based on the costume designer's initial visions. In both cases, we brainstormed potential solutions for characters and costumes that were already defined. This means the technical components had to be integrated into existing costumes. Once the costume designer had agreed on an initial proposal, we began discussing potential solutions with the other staff. We held separate meetings with the creative (e.g. tailor, design assistants) and technical (e.g. light technicians, engineers) employees. Shared meetings were not feasible due to busy schedules. It was our task to bring design and technology together while mediating all interests.

The Panda Show production had already started and the intern entered the ideation process when hearing that the costume designer wanted to have the eyes in the panda head glow red. She proposed to the costume designer and director to enable the actor to switch it on and off. Both were open to this initiative. Normally the light technicians would have installed the red eyes.

Before the production of King Ubu started, the costume designer told the researcher she would like to have this character smoke out of his armpits and rear because this fits with his vulgar demeanor. She personally would not know how to realize this and would normally speak to the light technicians about such ideas. We started investigating potential technologies for smoke (e.g. tiny fog machines inside clothes, tube connections to a big machine backstage, ultrasound fog machines, smoke pellets or dry ice). After talking to the technicians we decided to integrate a tiny fog machine into the fat man suit because this seemed to be the most safe, elegant and effective solution.

\section{Development Phase}

In this stage, we first created low-fidelity prototypes to examine whether the technical concepts had the desired effect. We showed these to the creative and technical department before developing the final interactive prototypes that had to be integrated into the costumes. In this phase we still mediated between creative and technology interests. We mostly met separately with staff from each department to discuss aesthetical/design-related or functional/technical issues. Despite this separation, it was notable that both areas placed a major focus on robustness and safety of the costumes as a main requirement. In particular, discussions with the creative departments revealed that robustness of costumes is the most important issue. The tailor and the costume designer made clear that the audience's overall im- 


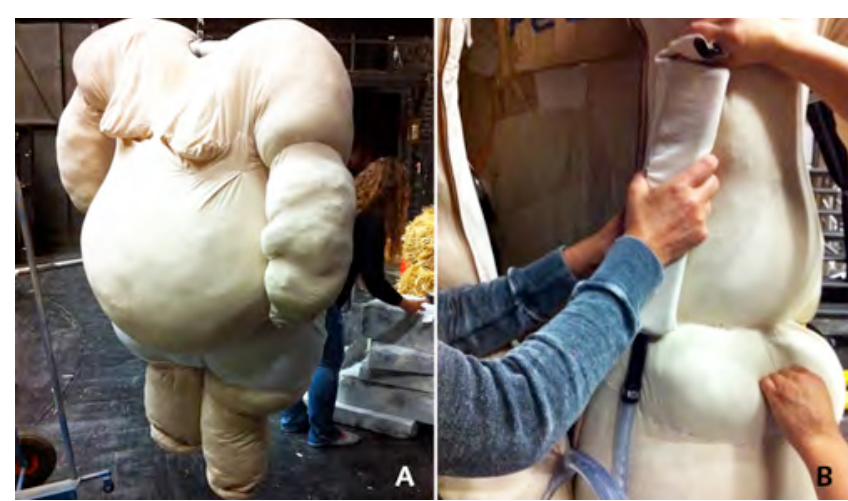

Figure 6. Fat suit (A) - integrating pipes and fog machine (B).

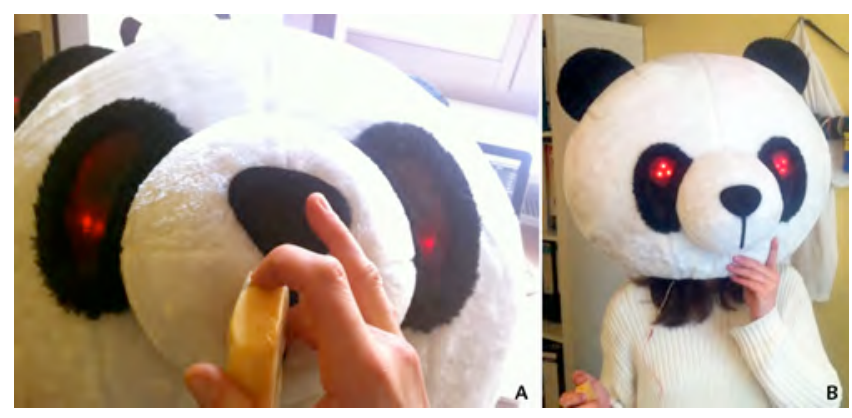

Figure 7. Panda mask - LEDs position before (A) and after (B).

pression of a play is central for a theatre house. If a costume breaks on stage, any positive effects are jeopardized.

When creating the red glowing Panda eyes for the Panda Show, there was no direct collaboration between technical and design development. This was surprising because the creative staff lacked knowledge of how to light up a LED. They only wanted the lights to be integrated well enough to outlast lively jumping, and to allow for quick changes of costume. The technicians, not being very interested in creating such a simple and not technically challenging feature, deferred the task to the intern and supported her only after repeated requests. After having finished a prototype with a 3-LED matrix per eye wired to a button hand piece that could be hidden inside the costume sleeve, the intern (and not the tailor who argued it was not in her work responsibility to work with technological elements) integrated the technology into the head. But because design and technology did not work together, the development was not really successful. It took three weeks to realize, and was finished only a day before the premiere. We believe it could have been done much earlier if both departments would have worked closer together. The director finally decided to not use the interactive eyes on stage. We therefore removed the button and installed an on-off switch that had to be en/disabled before the actor put the head on.

In contrast, the development process of King Ubu's smoke costume was more collaborative. After producing a lowfidelity prototype that resulted in a pipe system for safely distributing smoke, we conducted several technical tests where different persons responsible took part (costume designer, tailor, assistant, light technician, engineer). For testing there were shared meetings with creative and technical staff. For more specific technical questions, we only met the technicians who had relevant expertise. Simultaneously, we continued communicating individually with the costume designer and tailor that developed a solid solution for including the pipes and the tiny fog machine into the fat suit (figure 6B). The fog machine was integrated into a pocket consisting of an inner layer of fire-safe fabrics and an outer cover from skin-colored fabrics. Robustness was a major requirement because Ubu goes wild during the performance, and the integrated fog machine needs to be refilled and recharged after every performance. We mediated the process and, together with the tailoring department and the technical staff, solved how to integrate the components into the fat suit. We believe this resulted in a robust interactive costume, and consequently, collaboration with all departments was essential. Nevertheless, the process took a long time, for several reasons. Firstly, the production was large. Once a year, the theatre house produces a large open air play, with more than 50 background actors and a stage about three-times larger than for ordinary. Thus, the human resources of this institution were at their limits and creating this interaction never had priority. Secondly, it was a challenge to find a robust, safe and invisible solution for integrating the machine into the suit. The safety checks had to be done with the technicians and the integration into the textiles was carried out with the tailors. Both tasks took time when the staff was busy with many other things.

\section{Deployment/ Staging Phase - Revealing Frictions}

The advantage of collaborating with the theatre was that we received stakeholder feedback at various points during the design, so we could improve designs and interaction concepts early-on. Here, the actors as wearers of the costumes were involved, bringing us towards deployment. Since rehearsals already ran in parallel to the development, there was an overlap between both phases. In both productions, we visited the early rehearsals to understand the characters and how the actor plays (as it is common in costume design [14]). Costumes were not worn in these early stages, but both actors much later had rehearsals where they wore the costume and thus inhabited another body format (both costumes had an extraordinary shape). After confirming the actors handedness, we decided with the costume designer to integrate the triggers for activating interactive features next to their left hands, so that the actors were still able to use their right hand freely.

Unfortunately, in both production processes, the creative direction finally decided against staging the interactive features since the actors were not fully familiar with them, and therefore the effects were not deemed useful enough for the play. The actual staging of interactive costumes thus is another challenge next to the development process. While the actors (who are the 'end users'), as professionals are used to 
wear any kind of garment and trained to assume various roles, wearing interactive costumes is a novel experience for them as they have to act intentionally with these. The actors need time to experiment with these novel costumes to explore how they can enhance their role. But in our case, the actors were hardly involved in the creation and rehearsing with the interactive costumes started very late (in both cases just a week before the premiere, which is normal [14]). Next to technical problems, these are the main reasons why the interactive elements were not staged. We assume that early rehearsals with the interactive features would have allowed for their successful staging. Overall, while in both cases the costumes ended up not being staged, analysis of the causes led to valuable insights.

For the Panda Show, director, stage and costume designer seemed to be very open to the idea of integrating interactive features into the Panda's costume whereas the actor remained skeptical. Initially, while rehearsing with the costume on, he criticized the integration of the interactive eyes; then the cable was too short, then he said the position of the LEDs obstructed his view. Thus, we moved them to keep his field of view free (figure 7A/B). He also provided critique without trying on the panda head. Feedback from the director, stage and costume designer was more helpful because they exactly explained what to improve, e.g. using more LEDs to intensify the glowing eyes. Early-on we discussed the idea of interactive control with the actor who thought it would be sufficient to switch the red eyes on or off before coming on stage. But the director supported our idea. Yet one day before the premiere, he nevertheless decided for a non-interactive solution. We assume the main reason was that the actor did not have enough rehearsals with the interactive costume and therefore was neither familiar nor comfortable with the feature. The costume designer, when talking about the interactive costumes to the researcher, said: "it's always good to test things with [the actor], so that he immediately knows how it works", which indicates that actors generally need time to rehearse with a costume. This is very likely even more important if a costume contains novel interactive features.

The actor of King $U b u$ raised safety concerns after seeing the pipe system for distributing the fog inside the suit for the first time. He was afraid the synthetic wool in the suit could burn or melt and hurt him. We decided to run a safety test with the actor to address his concerns. A light technician who is an expert for fog machines explained how it works and that nothing is flammable since the machine works with steam (not smoke). We could only relax the actor's worries with an extended test, letting the fog machine smoke directly into the wool and fabric for several minutes. Nothing happened. Another challenge concerned other stakeholders: The fog machine inside the costume had to be refilled and its battery recharged after every show and it was not clear whose responsibility this task was - the light technician who normally cares for the larger fog machines or the dresser who sorts and cleans the costumes after every show? We finally found a compromise and planned to position a chair next to the costume's backstage location where the handover of the fog machine should always took place. The technician should refill and charge the device, and the dresser's task was to insert it into the costume and take it out again. Unfortunately, there were only two rehearsals with the interactive costume that then worked not properly. We could not attend these, but later-on, we talked to the costume designer and light technician to find out what happened, and why the smoke feature had not been staged. The costume designer reflected on this from a socio-political viewpoint. She said that in both rehearsals the effect was not properly visible from the audience viewpoint, even though the actor had activated it. As the costume designer also had to care for many other issues during and after rehearsals, there was no capacity to check why the smoke did not appear. Also, the actor already was under pressure because he had to wear a heavy fat man suit in summer. Furthermore, he seemed to not feel comfortable with the smoke feature. The decision of the director and costume designer to not stage the smoke effect was due to all of this. The lighting technician analyzed the situation purely from a technical perspective. He assumed that the fog machine was possibly inserted in too many fabric layers and did not get enough air supply, and that laying the device vertically instead of the usual horizontal position may have led to dysfunction. He was right; we had lacked the time to test the machine in these conditions, and had only done component testing, but not tested the integrated final system.

\section{Lessons Learned}

Though the creative department had hardly any technological knowledge and totally relied on the technical staff, they were open-minded, especially when interactive effects could expand expressive abilities of a role. During a production, the processes of designers and technical staff are strictly separated by traditional organizational structures as well as definitions of responsibilities and competences that do not support early collaboration or border-crossings. Nevertheless, an early cooperation can create synergy effects and result in a time-/content-efficient production. A person/group with a bridging role can be instrumental when interactive costumes are to be developed with several departments. Beyond that, individual meetings are necessary to solve smaller problems related to specific expertise.

Besides creating interactive costumes, staging them is another challenge and potentially risky, especially since actors are not used to wear computational clothes even though they are trained to adapt to new situations. They may have concerns or fears that make them feel uncomfortable or unsafe. Thus, we need to help them overcome these at an early stage by discussing and testing everything. Rehearsing with interactive costumes is important and should commence early-on. Robustness and security are major requirements for crafting and staging costumes. Moreover, creative and technical departments can provide helpful feedback for 
construction of and workflow with interactive costumes. Also, staging interactive costumes can result in novel situations that do not fit the normal workflow of traditional theatres and therefore demands new tasks from the staff. Then it needs mediation between the different interests.

\section{DISCUSSION AND CONCLUSIONS}

Integrating technology into costumes is a challenge for theatre houses. The studies presented here - conducted in the very different contexts of a self-directed student project and a collaboration with a local theatre house - illustrate this. The main findings concern the lack of integrated collaboration processes between designers and engineers in theatres, the actors as users who need knowledge on interactive costumes as well as more time for dress rehearsals, and continuity of conventional costume requirements (role-support, robustness, security, perceptibility).

A general function of theatre costumes is to support the actors in playing a role, in particular by affecting appearance, movement and posture [14]. Interactive costumes need to do this as well. Gonzales et al., who studied interactive projections, suggest the design principle Augmented Expression [10]: "technology should enrich the mediums of expression" (which is also relevant for other stakeholders e.g. choreographers). But, as we further found, costume tends to have a minor function in theatre and is subordinate to playing a role, and the overall performance. Individual effects are secondary to this. In contrast, Gonzales et al. argue for Aesthetic Harmony, where performer and manipulated effects should "complement each other to create an integrated aesthetic" [10]. This may be relevant for dance, but based on our experiences we believe this is rarely necessary for theatre performances. To support acting and not interfere with the overall play, interactive costumes need to be intuitive and easy to use and to provide adequate feedback on interaction. Moreover, while the student project had already revealed the importance of robustness, the theatre collaboration revealed this to be even more crucial, and pressed safety as a core issue for staging interactive costumes.

Furthermore, we found that perceptibility of interactive effects from a spectator's perspective is crucial to successfully stage interactive costumes. Arguing with Reeve's magical spectator experience [22], we think for theatre plays the audience does not need to understand how manipulation works. In contrast, Gonzales et al. pose the Connected Kinetics principle, which means the audience should be able to understand not only effects but also manipulations [10].

Both our studies suggested that actors should have sufficient time to train with the interactive features and rehearse while wearing the costumes and possibly should also be included in the creation process. While the student project only indicated this to be useful, the collaboration with the theatre house revealed it to be essential, as actors can be the show-stopper if they do not feel comfortable and safe, or their ability to act is hindered. Early rehearsals are not only important for actors in learning to deal with technology issues and errors, but also provide an opportunity to gain their feedback to improve the costume design. This is similar to what Latulipe et al. [18] found for dance performances with interactive projections.

From our second study we conclude that for creating, staging, and maintaining interactive costumes, professional theatres would have to adapt to enable more direct collaboration between departments. The self-directed student project had developed its own interdisciplinary routines in a tightly connected process. This shows how design and technology can go hand in hand. Gonzales et al.'s principle Integrated Process [10] also argues for a tight connection, in particular for the involvement of engineers in design. Latulipe et al. further argue that all stakeholders should be involved in all rehearsals and that interactive costuming "may actually require a longer production cycle" [18]. The integrated processes that interactive costumes require, challenge the traditional organizational structures of theatre houses. As we saw in our projects, technology features need to be considered in the early costume design, but also in staging and maintaining costumes. Interactive costumes integrate technology and art/craft and thus concern several departments, when these are all historically different responsibilities and the departments only rarely interact (cf. [14]). It is not easy to change these structures, as this interferes with established skill sets, professional roles, and might even create new workflow problems elsewhere. One solution, exemplified in our external designer, would be the creation of a new responsibility and role that mediates between departments. This has also been suggested by Ha and Kim [11], who explore the design process of wearable computers for performances. However, this is a pragmatic solution and may be more of a work-around. A suggestion for a long-term solution would be to train both creative and technical staff in the other areas for a better mutual understanding. Our student project showed that collaborative creative work not only supports mutual understanding, but also results in shared (creative) ownership. We found the early activity workshops to be highly important, where all sides brought in ideas, and then wanted to contribute to their realization. While for a teaching project approaches such as the designacting workshop are useful, other activities might be more appropriate within the theatre process.

One of our suggestions for future research is to involve actors early-on in iterative design. But how would we go about this? For a fully user-centered or participatory process they should be involved already during ideation. This may not be straightforward, as actors tend to be very busy, rehearsing several plays in parallel to staging others, may not be used to being involved in such decisions, and in general we do not yet know much about the actors' viewpoint. Another limitation of our work is that we only collaborated with one theatre. Plans for future work include attaining insight into other theatre houses of different size, investigating the viewpoints of producers and actors, as well as 
studying the audience perception of interactive costumes. Longer-term studies could focus e.g. on costume maintainance. Finally, an open question is whether the organizational structures of Ballet or Opera provide similar challenges.

Concluding, we have provided real-world case studies of wearables in the theatre domain. These revealed requirements and challenges for the design process as well as the effective staging of interactive costumes, the biggest challenge being how to integrate these into existing infrastructural structures of traditional theatre houses. We also suggested initial solutions to these challenges

\section{ACKNOWLEDGMENTS}

Special thanks goes to Theaterhaus Jena, in particular costume designer V. Bleffert, our project students (H. Abitz, G.D. Acay, M. Al-Hallak, S. Gottschlich, S. Luge, W. Müller, T. Rückert, H. Sahibzada, M. Schmandt), the theatre pedagogue (J. Hahn), and the actors (C. Kneisz, M. Oehlke, R. Ecker). The Frauenförderfonds of Bauhaus-Universität Weimar supported the student project with funding.

\section{REFERENCES}

1. Barnett, A. The dancing body as a screen: Synchronizing projected motion graphics onto the human form in contemporary dance. Computers in Entertainment (CIE) 7, 1 (2009), Article No. 5.

2. Benford, S., Giannachi, G. Interaction as Performance. interactions 19, 3 (2012), 38-43.

3. Berzowska, J., Memory Rich Clothing: Second Skins that Communicate Physical Memory. Proc. C\&C 2005, ACM 2005, 32 - 40.

4. Birringer, J., Danjoux, M. The Sound of Movement Wearables. LEONARDO 46, 3 (2013), 232-240.

5. Buechley, L., Eisenberg, M. Fabric PCBs, Electronic Sequins, and Socket Buttons: Techniques for E-Textile Craft. Pers. Ubiq. Computing 13, 2 (2009), 133-150.

6. Cheng, S.H., Kim, K., Vertegaal, R. TagURit: a proximity-based game of tag using lumalive e-textile displays. Proc. CHI 2011 EA, ACM 2011, 1147-1152.

7. Dalsgaard, P. Research In and Through Design - An Interaction Design Research Approach. Proc. OZCHI 2010, ACM 2010, 200-203.

8. Friedrichs-Büttner, G., Walther-Franks, B., Malaka, R. An unfinished drama: designing participation for the theatrical dance performance Parcival XX-XI. Proc. DIS 2012, ACM 2012, 770-778.

9. Gobo, G. Doing Ethnography. SAGE, London, UK, 2010.

10. Gonzalez, B., Carroll, E., Latulipe, C. Dance-Inspired Technology, Technology-Inspired Dance. Proc. NordiCHI 2012, ACM 2012, 398-407.

11.Ha, Y.-I, Kim, Y.-K. The Design Process of Wearable
Computers for Extending the Performer's Expression. HCI International 2014 EA, 2014, 421-426.

12. Harrison, D., Marshall, P., Berthouze, N., Bird, J. Tracking Physical Activity: Problems Related to Running Longitudinal Studies with Commercial Devices. Proc. UbiComp 2014, ACM 2014, 699-702.

13. Hayes, G.R. The Relationship of Action Research to Human-Computer Interaction. ACM TOCHI 18, 32011 , Article No. 15.

14. Holt, M. A Phaidon Theatre Manual-Costume and Make-Up. Phaidon Press Limited, London, UK, 2012.

15. Juhlin, O., Zhang, Y., Sundbom, C., Fernaeus, Y. Fashionable shape switching: explorations in outfit-centric design. Proc. CHI 2013, ACM 2013, 1353-1362.

16. Ka, W. Man in lelspace.mov / Motion Analysis in 3D Space. Proc. MULTIMEDIA '05, ACM 2005, 590-593.

17. Kittleson, H., McCarthy, M. Pert and Plays: Project Management in the Theatre Arts. Educational Theatre Journal 25, 1 (1973), 95-101.

18. Latulipe, C., Wilson, D., Huskey, S., Gonzalez, B., Word, M. Temporal Integration of Interactive Technology in Dance: Creative Process Impacts. Proc. $C \& C$ 2011, ACM 2011, 107-116.

19. Mauriello, M., Gubbels, M., Froehlich, J.E. Social fabric fitness: the design and evaluation of wearable E-textile displays to support group running. Proc. CHI 2014, ACM 2014, 2833-2842.

20. Olsson, T. Arduino Wearables. Apress, New York, USA, 2012.

21. Owen, C.B., Dobbins, A., Rebenitsch, L. Theatre Engine: Integrating Mobile Devices with Live Theater. Proc. MoMM 2013, ACM 2013, 378-386.

22. Reeves, S., Benford, S., O'Malley, C., Fraser, M. Designing the Spectator Experience. Proc. of CHI 2005, ACM 2005, 741-750.

23. Salter, C. Entangled: Technology and the Transformation of Performance. MIT Press, Cambridge, 2010.

24. Saltz, D.Z. Live Media: Interactive Technology and Theatre. Theatre Topics 11, 2 (2001), 107-130.

25. Schleicher, D., Jones, P., Kachur, O. Bodystorming as Embodied Designing. interactions 17, 6 (2010), 47-51.

26. Suchman, L. Plans and situated actions. Cambridge University Press, New York, USA,1987.

27. Torpey, P.A., Jessop, E.N. Disembodied performance. Proc. CHI 2009 EA, ACM 2009, 3685-3690.

28. Wilde, D., Cassinelli, A., Zerroug, A. Light Arrays. Proc. CHI 2012 CHI EA, ACM 2012, 987-990.

29.Zimmerman, J., Forlizzi, J., Evenson, S. Research through design as a method for interaction design research in HCI. Proc. CHI 2007, ACM 2007, 493-502. 